\title{
Biologia floral de Manilkara subsericea e de Sideroxylon obtusifolium (Sapotaceae) em restinga ${ }^{1}$
}

\author{
REJANE GOMES ${ }^{2,3,4}$, MARIA CÉLIA BEZERRA PINHEIRO², HELOÍSA ALVES DE LIMA² e \\ LYGIA DOLORES RIBEIRO SANTIAGO-FERNANDES ${ }^{2}$
}

(recebido: 19 de abril de 2007; aceito: 25 de março de 2010)

\begin{abstract}
Floral biology of Manilkara subsericea and Sideroxylon obtusifolium (Sapotaceae) in restinga). Manilkara subsericea (Mart.) Dubard and Sideroxylon obtusifolium (Roem. \& Schult.) T.D. Penn. display inflorescences of a fasciculate type, with perfect, nectariferous, odoriferous and hercogamous flowers. They present protogynic dichogamy and daylight anthesis. The corolla is gamopetalous, with the basal region of the lacinia forming a small tube. The medial lacinia, in both species, curves toward the flower axis, forming a type of groove, in which the stamen is lodged. The anthers are versatile, extrorse, and rimose. Pollen grain release is cloud-like, on account of an explosive mechanism upon activation of the lacinia-stamen device. The flowers were visited by bees, butterflies, beetles, flies and Thysanoptera, being pollinated by Xylocopa ordinaria and Apis mellifera bees, by the Brachygastra lecheguana wasp and by the Isanthrene incendiaria butterfly.
\end{abstract}

Key words - explosive release of pollen, floral biology, Manilkara subsericea, Sapotaceae, Sideroxylon obtusifolium

RESUMO - (Biologia floral de Manilkara subsericea e de Sideroxylon obtusifolium (Sapotaceae) em restinga). Manilkara subsericea (Mart.) Dubard e Sideroxylon obtusifolium (Roem. \& Schult.) T.D. Penn. apresentam inflorescências fasciculadas, com flores perfeitas, nectaríferas, odoríferas e hercogâmicas. Apresentam dicogamia protogínica e antese diurna. A corola é gamopétala, com a região basal dos lacínios formando um pequeno tubo. Os lacínios medianos, em ambas as espécies, curvam-se em direção ao eixo da flor, formando uma espécie de canaleta, na qual fica alojado o estame. As anteras são versáteis, extrorsas e rimosas. A liberação dos grãos de pólen ocorre na forma de nuvem por um mecanismo explosivo proveniente do acionamento do dispositivo lacínio-estame. As flores foram visitadas por abelhas, borboletas, besouros, moscas e Thysanoptera, sendo polinizadas pelas abelhas Xylocopa ordinaria e Apis mellifera, pela vespa Brachygastra lecheguana e pela borboleta Isanthrene incendiaria.

Palavras-chave - biologia floral, liberação explosiva de pólen, Manilkara subsericea, Sapotaceae Sideroxylon obtusifolium

\section{Introdução}

Manilkara Adans. e Sideroxylon L. são gêneros de Sapotaceae com 35 e 75 espécies, respectivamente, de hábito arbóreo e arbustivo, distribuídas nas regiões tropicais e subtropicais (Reitz 1968, Pennington 1990, Judd et al. 1999, Ferreira 2000).

Manilkara subsericea (Mart.) Dubar e Sideroxylon obtusifolium (Roem. \& Schult.) T.D. Penn. subsp. obtusifolium, aqui estudadas, são táxons bem representados no Brasil, o primeiro em vegetação de restinga e florestas pluviais e o segundo praticamente exclusivo da restinga, onde tem como habitat as dunas pouco onduladas e fixas (Reitz 1968, Pennington 1990, Ferreira 2000). Manilkara subsericea ocorre

1. Parte da tese de doutorado da primeira autora, Programa de Pós-Graduação em Botânica, Museu Nacional, Universidade Federal do Rio de Janeiro, Rio de Janeiro, RJ, Brasil.

2. Universidade Federal do Rio de Janeiro, Departamento de Botânica, Museu Nacional, Quinta da Boa Vista, 20940-040 São Cristóvão, RJ, Brasil.

3. Universidade Federal Rural do Rio de Janeiro, Instituto de Biologia, Departamento de Botânica, BR-465, km 7, 23890-000 Seropédica, RJ, Brasil

4._Autora para correspondência: rejanegome@gmail.com desde Pernambuco até Santa Catarina, enquanto que Sideroxylon obtusifolium é registrada do Ceará ao Rio Grande do Sul (Reitz 1968, Pennington 1990, Ferreira 2000). Nas restingas do Estado do Rio de Janeiro, $M$. subsericea pode ser encontrada do Município de São João da Barra até Maricá. Já S. obtusifolium é registrada, ao longo do litoral fluminense, desde São João da Barra até Macaé e de Cabo Frio até Mangaratiba (Pennington 1990, Ferreira 2000, Silva \& Oliveira 2001).

Estudos sobre a biologia floral, a polinização e o sistema sexual de espécies da família Sapotaceae, em geral, limitam-se a uma abordagem superficial, muitas vezes diluída em levantamentos florísticos, estudos reprodutivos envolvendo grandes comunidades vegetais ou aqueles relacionados com a taxonomia da família. Nesse contexto, ocorrem os registros de protoginia para Manilkara bahamensis (Baker) H. J. Lam \& A. Meeuse e Bumelia salicifolia (L.) Sw. (= Sideroxylon salificifolium (L.) Lam.) (Tomlinson 1974), bem como a presença de auto-incompatibilidade para Manilkara zapota (L.) P. Royen, Argania spinosa (L.) Skeels e Madhuca indica J. F. Gmel. (Bawa 1974, Kuruvilla \& Shah 1988, Nerd et al. 1998). Particularmente, no que se refere à polinização das flores de Sapotaceae, são comuns sugestões e 
inferências sobre a polinização das espécies, a partir de características florais como cor, forma, horário de antese e liberação de odor, sempre acompanhadas de expressões que denotam dúvida (Ormond et al. 1993, Nerd et al. 1998, Hansman 2001). Os polinizadores, assim referidos, incluem desde pequenos insetos, como Thysanoptera, abelhas, besouros e moscas, até pássaros, morcegos e marsupiais (Pennington 1990). A polinização pelo vento também é citada para Madhuca indica e Mimusops elengi L. (Heithaus et al. 1975, Subba Reddi \& Atluri 1981, Kuruvilla 1989, Ribeiro et al. 1999, Hansman 2001).

Algumas espécies desta família são incluídas em listas de espécies ameaçadas de extinção. As duas espécies aqui estudadas, por se localizarem no litoral, área de grande valorização imobiliária, vêm tendo seu habitat dizimado. Manilkara subsericea está classificada como rara (R), segundo o "Red Data Book" (IUCN 1998 apud Ferreira 2000), enquanto Mello-Filho et al. (1992) e Ibama (1992) registraram Sideroxylon obtusifolium (como Bumelia obtusifolia) como vulnerável (V) na publicação Centuria Plantarum. Entre as medidas que favorecem a conservação destas espécies em áreas do Estado do Rio de Janeiro, destaca-se a presença das mesmas na Área de Proteção Ambiental (Apa) de Maricá, no Parque Natural Municipal de Grumari e no Parque Nacional da Restinga de Jurubatiba (Parna); ambas as espécies encontram-se também representadas no Jardim Botânico do Rio de Janeiro e S. obtusifolium é amplamente utilizada no paisagismo do Parque do Aterro do Flamengo (Mello-Filho et al. 1992, Ferreira 2000).

Os fatores assinalados acima constituem um forte incentivo para a condução de estudos reprodutivos em Sapotaceae, especialmente naquelas espécies ocorrentes em vegetação de restinga. As flores de $M$. subsericea e de S. obtusifolium, assim como as de muitas outras espécies da família, apresentam um estádio do desenvolvimento dos botões em que o estilete e a área estigmática são exteriorizados. Tomlinson (1974) em estudo sobre mecanismos de reprodução de árvores nativas da Flórida tropical, classificou Bumelia salicifolia (L.) Sw. e M. bahamensis, como dicogâmicas protogínicas por apresentarem esta característica de exteriorização estigmática. No entanto, a simples exteriorização do estigma não é garantia da receptividade do mesmo. A protoginia, até o momento, somente foi confirmada para Madhuca indica (Kuruvilla \& Shah 1988) e Argania spinosa (Nerd et al. 1998).

Este trabalho tem como objetivo estudar a morfologia, a biologia floral e a polinização de Manilkara subsericea e de Sideroxylon obtusifolium na restinga de Maricá (RJ). Embora de gêneros diferentes, as flores das duas espécies compartilham características morfológicas similares, principalmente relacionadas com a forma da corola e a exteriorização do estilete e do estigma nos botões. Além disso, as espécies apresentam mecanismo de liberação explosiva de grãos de pólen, ainda não registrado na literatura. As questões básicas que nortearam o presente estudo foram: 1) A exteriorização da área estigmática ainda no estádio de botão já caracteriza antese e, portanto, protoginia para M. subsericea e S. obtusifolium? 2) Que estruturas florais estão envolvidas e como estão organizadas para que ocorra a liberação explosiva dos grãos de pólen? 3) O mecanismo de liberação explosiva dos grãos de pólen nas flores de M. subsericea e S. obtusifolium depende de uma visita para ser acionado? 4) Quais visitantes florais são capazes de promover a liberação dos grãos de pólen e transferi-los para a área estigmática, sendo polinizadores efetivos das espécies em estudo?

\section{Material e métodos}

O estudo de Manilkara subsericea e de Sideroxylon obtusifolium foi desenvolvido em populações naturais da restinga de Maricá (RJ), através da observação dos indivíduos em duas localidades: na Área de Proteção Ambiental (Apa) e em Itaipuaçu, área loteada, com pequenos fragmentos de vegetação de restinga, no período de janeiro de 2003 a dezembro de 2005.

Sideroxylon obtusifolium é um arbusto, com cerca de 1,5 m, que ocorre sobre o cordão externo; $M$ subsericea está presente no cordão interno e apresenta hábito arbóreo, com cerca de $2 \mathrm{~m}$. Esta última espécie também é encontrada no cordão externo, onde exibe hábito arbustivo, com cerca de $0,5 \mathrm{~m}$.

A precipitação pluviométrica é concentrada no verão e reduzida no inverno, com média anual de $1.030 \mathrm{~mm}$. A temperatura média anual é de $23,6^{\circ} \mathrm{C}$, não sendo registrada uma estação seca (Mantovani \& Iglesias 2001).

O estudo da biologia floral foi realizado através da análise morfológica das flores, registrando-se, ainda, as atividades referentes aos períodos de pré-antese, antese e pósantese, destacando-se os seguintes eventos: abertura floral, deiscência das anteras, mecanismo de liberação dos grãos de pólen, presença de grãos de pólen nas anteras após visita, receptividade do estigma, liberação do odor e longevidade das flores. O número de flores por inflorescência foi obtido a partir da média de 10 inflorescências em diferentes indivíduos.

A área estigmática foi caracterizada morfologicamente e fisiologicamente de acordo com Heslop-Harrison \& Shivanna (1977) e o estudo do tecido de transmissão e do canal estilar segundo Endress (1994), em 10 flores. Para determinar a receptividade do estigma foram considerados os seguintes indicativos: presença de secreção observada a olho nu e aderência e germinação de grãos de pólen em microscópio estereoscópio e ótico. Flores de cada espécie ( $n=10$ flores de 
cinco indivíduos) foram coletadas e fixadas em álcool + ácido acético (3:1) (Levin \& Berube 1972), para a quantificação de grãos de pólen e observação dos tubos polínicos presentes na área estigmática de botões com estilete exteriorizado e de flores em antese. A ocorrência de secreção lipídica sobre a exina dos grãos de pólen foi testada com Sudan III e IV (Johansen 1940). O índice de viabilidade dos grãos de pólen foi calculado a partir de coloração com carmin acético (Alexander 1980). Os grãos de pólen, não acetolizados, foram medidos em microscópio ótico.

A presença de odor foi testada dissecando-se os verticilos florais e colocando-os em diferentes recipientes de vidro, mantidos fechados por cerca de 20 minutos e, em seguida, utilizados para detectar a emissão de odor por essas estruturas. A presença de osmóforos foi testada usando-se solução de vermelho neutro, em cinco flores recém abertas. Após 15 minutos, as flores foram lavadas em água destilada e verificados os locais corados (Vogel 1983).

A concentração de açúcares no néctar foi aferida no campo, aproximadamente às $9 \mathrm{~h} 00$, em 30 flores recém abertas e previamente ensacadas, com o auxílio de refratômetro de bolso Atago Hand Refractometer N1.

Para a análise anatômica do estigma, as flores foram fixadas imediatamente após a coleta, em paraformaldeído $4 \%+$ glutaraldeído $2,5 \%$ em tampão fosfato de sódio $0,05 \mathrm{M} \mathrm{pH} \mathrm{7,2} \mathrm{e} \mathrm{submetidas} \mathrm{à} \mathrm{baixa} \mathrm{pressão.} \mathrm{As} \mathrm{amostras}$ foram desidratadas em série alcoólica, com passagem por clorofórmio, emblocadas (Historesina ${ }^{\circledR}$ Leica) e seccionadas em micrótomo rotativo (Spencer) com navalha de vidro. Secções de 1-3 $\mu \mathrm{m}$ de espessura foram coradas com Azul de Toluidina (Gahan 1984).

As observações dos visitantes florais foram realizadas no horário das $6 \mathrm{~h} 00$ às 20h00, durante os episódios de floração, registrando-se o horário das visitas, a frequência, o comportamento e a área de contato com as estruturas reprodutivas, bem como se as visitas resultavam na liberação explosiva dos grãos de pólen. Os visitantes foram classificados como: a) polinizadores efetivos (Pe) - visitantes capazes de acionar o mecanismo de liberação explosiva dos grãos de pólen e contactar o estigma durante as visitas; b) polinizadores ocasionais (Po) - visitantes capazes de acionar o mecanismo de liberação explosiva dos grãos de pólen e contactar o estigma apenas ocasionalmente nas visitas e c) pilhadores $(\mathrm{Pi}$ - visitantes que roubam néctar ou pólen, sem contactar anteras e estigmas. Os visitantes também foram classificados de acordo com suas frequências às flores (em 53 horas de observações), como: (1) pouco frequentes $(<50 \%)$; (2) frequentes $(\geq 50 \%$ e $<90 \%)$; (3) muito frequentes $(\geq 90 \%)$. Os insetos observados foram coletados com saco plástico e, no laboratório, foram medidos e analisados quanto à presença e à localização de grãos de pólen das espécies em estudo, utilizando-se microscópio estereoscópio e ótico. Posteriormente, os insetos foram montados e enviados aos especialistas para identificação.

As exsicatas das plantas estudadas foram depositadas no Herbário do Museu Nacional (R) e os insetos coletados encontram-se na coleção do Laboratório de Biologia da Reprodução do Museu Nacional/UFRJ.

\section{Resultados}

As flores de Manilkara subsericea e de Sideroxylon obtusifolium estão reunidas em inflorescências axilares e fasciculadas. Em M. subsericea são emitidas, em média, sete flores por inflorescência (tabela 1), as quais apresentam longos pedicelos (aproximadamente de $16 \mathrm{~mm}$ ) e são pêndulas; em S. obtusifolium ocorrem seis flores por inflorescência (tabela 1), com pedicelos mais curtos (cerca de $5 \mathrm{~mm}$ ). Nas duas espécies, as inflorescências estão distribuídas próximas umas das outras ao longo dos ramos, caracterizando uma alta densidade floral (figuras 1a, 2a).

As flores de M. subsericea e S. obtusifolium são actinomorfas, perfeitas, diurnas, nectaríferas, odoríferas, hercogâmicas e protogínicas. $\mathrm{O}$ experimento envolvendo a percepção de odor nas flores em estudo evidenciou a liberação de aroma doce e suave na corola. $\mathrm{O}$ teste com vermelho neutro indicou a possível ocorrência de glândulas de odor, os osmóforos, nos lacínios.

Manilkara subsericea tem flores creme-amareladas, com 9,2 mm de diâmetro e 7,3 mm de comprimento (tabela 1). O cálice é dialissépalo (figuras 1b-c), de cor verde claro, bisseriado, com três sépalas internas e

Tabela 1. Dados comparativos (média \pm desvio padrão) sobre o número de flores por inflorescência $(n)$, tamanho das flores e de estruturas florais (mm) de Manilkara subsericea e Sideroxylon obtusifolium na restinga de Maricá, Rio de Janeiro $(n=10)$.

Table 1. Comparative data (average \pm standard deviation) on the flowers number per inflorescence $(n)$, flowers and floral organs size (mm) of Manilkara subsericea and Sideroxylon obtusifolium in restinga of Maricá, Rio de Janeiro $(n=10)$.

\begin{tabular}{lcr}
\hline Dados comparados & $\begin{array}{r}\text { Manilkara } \\
\text { subsericea }\end{array}$ & $\begin{array}{r}\text { Sideroxylon } \\
\text { obtusifolium }\end{array}$ \\
\hline $\begin{array}{l}\text { Número de flores por } \\
\text { inflorescência }\end{array}$ & $7 \pm 2,93$ & $6 \pm 1,76$ \\
Pedicelo & $16 \pm 1,73$ & $5 \pm 0,13$ \\
Flor & $7,3 \pm 0,88$ & $6,9 \pm 0,10$ \\
Lacínio mediano & $4,3 \pm 0,24$ & $5 \pm 0,44$ \\
Cálice & $4,7 \pm 0,78$ & $3 \pm 0,38$ \\
Estilete & $3,6 \pm 0,72$ & $5,3 \pm 0,42$ \\
Ovário & $2 \pm 0$ & $1,7 \pm 0,61$ \\
\hline
\end{tabular}



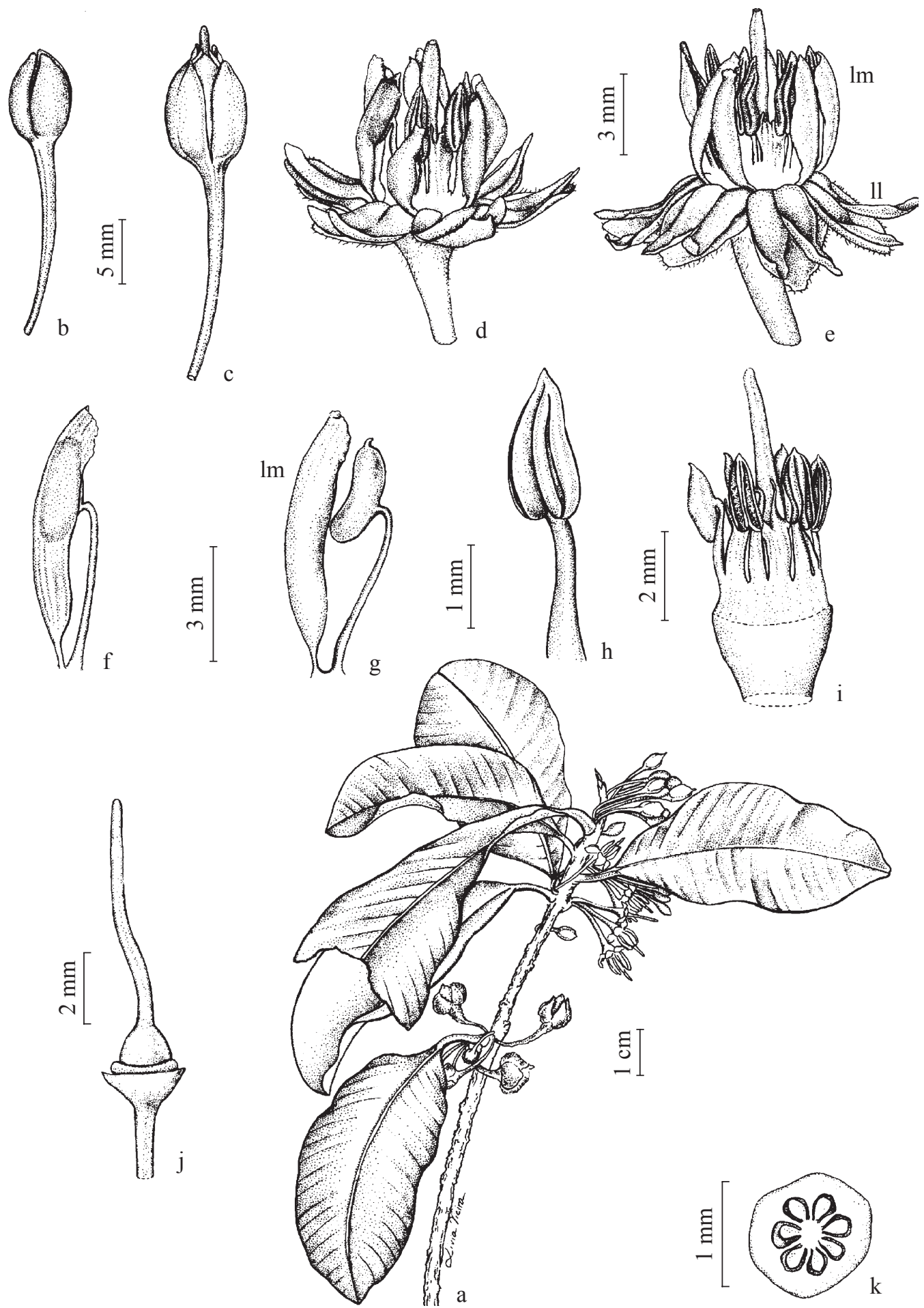

Figura 1. Manilkara subsericea. a. Ramo. b. Botão. c. Flor na fase feminina, com estilete exteriorizado. d. Flor na fase hermafrodita. e. Flor na fase hermafrodita com lacínios laterais (1l) deflexos e lacínios medianos (lm) com as anteras, notar a hercogamia. f-g. Acionamento do dispositivo lacínio-estame. h. Estame. i. Androceu. j. Gineceu. k. Ovário (corte transversal).

Figure 1. Manilkara subsericea. a. Branch. b. Bud. c. Flower in female phase, with external style. d. Flower in hermaphrodite phase. e. Flower in hermaphrodite phase with deflex lateral lacinia (1l) and medial lacinia $(\mathrm{lm})$ with the anthers, note herkogamy. f-g. Activation of the lacinia-stamen device. h. Stamen. i. Androecium. j. Gynoecium. k. Ovary (transverse section). 
três sépalas externas, cuculadas, com tricomas de cor marrom na superfície abaxial e 4,7 mm de comprimento. A corola é gamopétala, com seis pétalas, cada uma delas dividida em três segmentos: um mediano e dois laterais, aqui chamados de lacínios. Os seis lacínios medianos da corola posicionam-se internamente na flor, são eretos, lanceolados, apresentam 4,3 mm de comprimento e têm consistência crassa. Cada lacínio forma uma espécie de canaleta, voltada para o eixo floral, na qual um estame fica alojado sob tensão, constituindo este conjunto, lacínioestame, um dispositivo que tem que ser acionado para ocorrer a liberação explosiva de grãos de pólen. Cada flor apresenta, portanto, seis desses dispositivos (figuras 1d-f). Os 12 lacínios laterais, por sua vez, apresentam cerca de 4,0 mm de comprimento, são membranáceos, cuculados e assumem uma posição externa e deflexa nas flores. Estes lacínios encontram-se posicionados sobre as sépalas - dois lacínios laterais sobre cada sépala - e alternados por um lacínio mediano (figuras 1d-e).

$\mathrm{O}$ androceu possui seis estames alternados com seis estaminódios, é epipétalo e conato em sua parte basal (figura 1i), contribuindo para a formação de um pequeno tubo floral, com $3,7 \mathrm{~mm}$ de comprimento. Cada estame é constituído por um filete branco, com porção livre de $2 \mathrm{~mm}$ de comprimento e uma antera amarela, rimosa, versátil, dorsifixa e extrorsa (figuras 1f-h) que, mesmo deiscente, só dispersa seus grãos de pólen quando liberada do lacínio mediano que a envolve. Os estaminódios são petalóides, com ápice bi ou tripartido. Os grãos de pólen medem $38 \mu \mathrm{m}(n=10)$, são brancos, secos, apresentam exina pouco esculturada e uma viabilidade de $91 \%$ ( $n=388$ grãos de pólen).

O conjunto lacínio-estame constitui um dispositivo semelhante a uma catapulta (figuras $1 \mathrm{f}-\mathrm{g}$ ), que depende de um fator físico para ser acionado, proporcionando a liberação dos grãos de forma explosiva. Quando o polinizador toca neste dispositivo e o impulsiona, o lacínio desloca-se para trás, acionando o dispositivo e ocasionando a explosão de uma "nuvem" de grãos de pólen. As observações no campo, utilizando-se tanto flores marcadas e disponíveis aos polinizadores quanto flores ensacadas, mostraram que: 1 . as anteras, mesmo depois de deiscentes, não liberam os grãos de pólen antes que os dispositivos lacínios-estames sejam acionados; 2 . a liberação dos grãos de pólen dá-se concomitantemente com o acionamento dos dispositivos; 3 . cada dispositivo pode ser acionado isoladamente pelos polinizadores, de modo que não há simultaneidade na liberação do pólen pelos seis estames de cada flor; 4. a "nuvem" de grãos de pólen resultante de uma visita pode alcançar botões e flores vizinhas; 5 . toda a carga de grãos de pólen é liberada no momento em que o polinizador aciona o dispositivo; 6 . as flores não visitadas permanecem com seus seis dispositivos intactos, mas, ao final da antese, flores ensacadas em processo de senescência apresentam dispositivos acionados, independentemente das visitas; 7. em raras ocasiões, na presença de vento forte, pode ocorrer o acionamento dos dispositivos, independente do impulso decorrente de uma visita.

O estigma é arredondado, lobulado, diminuto, com aproximadamente $0,36 \mathrm{~mm}$ de diâmetro $(n=10)$, do tipo papiloso e úmido. O canal estilar alcança a superfície estigmática, tem formato estrelar com seis a oito braços $(n=10)$ e apresenta lúmen pequeno e grande superfície. A epiderme que reveste o canal estilar é unisseriada e secretora, proporcionando um tecido de transmissão do tipo superficial. O exame de seções transversais do estigma e do estilete revela que o número de braços, seis a oito, da superfície estigmática receptiva e do canal estilar é equivalente ao número de lóculos do ovário.

O estilete tem cor esverdeada, possui 3,6 mm de comprimento $(n=10)$ e é persistente nos frutos. O ovário é súpero, com $2 \mathrm{~mm}$ de comprimento, com seis a oito lóculos e um óvulo por lóculo (figura $1 \mathrm{k}$ ). O nectário tem formato anelar e localiza-se na base do ovário (figura 1j). Em função do pequeno volume de néctar por flor, não foi possível quantificá-lo, tendo o néctar uma concentração de açúcares de 28,8\% ( $n=30$ flores).

Sideroxylon obtusifolium tem flores brancas, com 6,4 mm de diâmetro e 6,9 $\mathrm{mm}$ de comprimento (tabela 1) e, portanto, menores do que as de M. subsericea. $\mathrm{O}$ cálice é dialissépalo (figuras $2 b-2 c$ ), verde, com cinco sépalas, sendo duas externas e três internas com $2 \mathrm{~mm}$ e $3 \mathrm{~mm}$ e de comprimento, respectivamente. As sépalas são côncavas, carnosas na base e membranáceas no ápice.

Acorola é pentâmera, gamopétala, formando um tubo floral com 1,5 mm de profundidade e com lacínios livres. Cada pétala está dividida em três lacínios: um mediano e dois laterais (figuras 2f-i). Os lacínios medianos têm consistência crassa, $5 \mathrm{~mm}$ de comprimento e assumem uma posição externa e inclinada em relação ao eixo da flor. Os bordos destes lacínios formam uma espécie de canaleta, na qual fica alojado um estame (figuras 2d-g). À semelhança de M. subsericea, o conjunto lacínio-estame constitui um dispositivo que, ao ser acionado, libera os grãos de pólen de forma explosiva. Cada flor apresenta cinco dispositivos. Ressalta-se que a liberação explosiva dos grãos de pólen em forma de "nuvem" em S. obtusifolium não é tão facilmente visível quanto em $M$. subsericea. Os lacínios laterais são lanceolados, com 3,3 mm de comprimento, dispostos de 

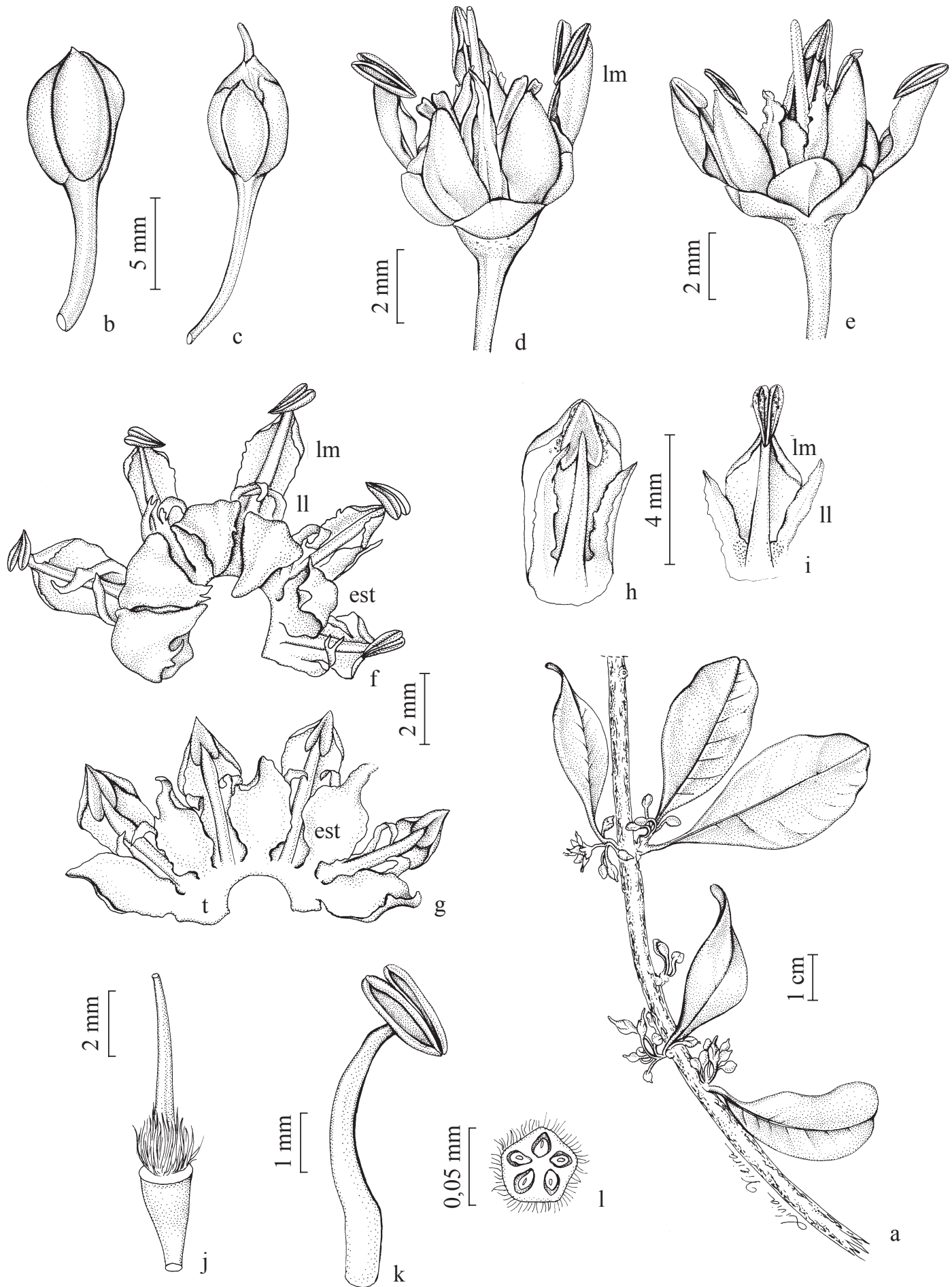

Figura 2. Sideroxylon obtusifolium. a. Ramo. b. Botão. c. Flor na fase feminina, com o estigma exteriorizado. d-e. Flor na fase hermafrodita, notar a disposição dos lacínios medianos (lm). f. Corola, estaminódios (est), lacínios medianos (lm) e laterais (11). g. Corola com os estaminódios e o tubo floral (t). h-i. Acionamento do dispositivo lacínio-estame. j. Gineceu. k. Estame. 1. Ovário (corte transversal).

Figura 2. Sideroxylon obtusifolium. a. Branch. b. Bud. c. Flower in female phase, with external style. d-e. Flower in hermaphrodite phase, note the disposition of the medial lacinia ( $(\mathrm{m})$. f. Corolla, staminodes (est), medial lacinia (lm) and lateral lacinia (1l). g. Corolla with staminodes and the floral tube (t). h-i. Activation of the lacinia-stamen device. j. Gynoecium. k. Stamen. 1. Ovary (transverse section). 
dois em dois ao lado de cada lacínio mediano (figuras $2 \mathrm{f}-\mathrm{g}$ ) e se relacionam com os atrativos florais.

$\mathrm{O}$ androceu é constituído por cinco estames e cinco estaminódios epipétalos. Os filetes são brancos e têm 3,9 mm de porção livre. Os estaminódios assumem uma posição interna, são petalóides, lanceolados, de consistência membranácea e alternos aos lacínios medianos. Apresentam 3,4 mm de comprimento e estão fletidos sobre o ovário nas flores (figuras $2 \mathrm{f}-\mathrm{g}$ ).

As anteras são amarelas, dorsifixas, extrorsas, versáteis e apresentam deiscência rimosa (figuras $2 \mathrm{i}, \mathrm{k}$ ). Os grãos de pólen são brancos, medem $26 \mu \mathrm{m}(n=10) \mathrm{e}$ têm uma viabilidade de $98 \%$ ( $n=447$ grãos de pólen).

O mecanismo de liberação dos grãos de pólen em S. obtusifolium é semelhante ao de M. subsericea. Para que o dispositivo lacínio-estame seja acionado, há a necessidade da presença de um polinizador capaz de tocar o ápice destes lacínios, provocando a soltura da antera e, consequentemente, a liberação de uma nuvem de pólen (figuras 2d-g). No entanto, em S. obtusifolium, mesmo após a liberação dos estames, os filetes permanecem alojados no lacínio mediano, enquanto que em M. subsericea os filetes são exteriorizados. Como em M. subsericea, nas flores senescentes não visitadas, os dispositivos também são acionados.

A morfologia do estigma de $S$. obtusifolium é semelhante à de $M$. subsericea; o estigma é do tipo papiloso, úmido, lobulado e diminuto, com aproximadamente $0,41 \mathrm{~mm}$ de diâmetro. $O$ canal estilar apresenta forma estrelar com cinco braços $(n=10)$. O estilete é branco, tem $5,3 \mathrm{~mm}$ de comprimento e é persistente no fruto. $\mathrm{O}$ ovário é súpero, com $1,7 \mathrm{~mm}$ de comprimento e 1,3 mm de diâmetro, pentalocular, com um óvulo por lóculo (figuras $2 \mathrm{j}, 1$ ) e com a superfície recoberta por tricomas de cor marrom, que se estendem até a região basal do estilete. O néctar é secretado em quantidades mínimas, sob a forma de gotículas, não tendo sido possível medir a sua concentração.

A abertura dos botões das espécies em estudo inicia-se em diferentes horas do dia. O processo é lento, estendendo-se por cerca de 21 horas em $M$. subsericea e 15 horas em S. obtusifolium. Em um determinado estádio do desenvolvimento do botão, próximo à abertura, ocorre a exteriorização do estigma, ainda não receptivo, caracterizando a fase de botão em pré-antese, para ambas as espécies.

O início da antese nas duas espécies é marcado pela receptividade estigmática, evidenciada pela presença de secreção e pelo intenso brilho do estigma exteriorizado, embora a corola encontre-se fechada, sem eliminação de odor e sem secreção de néctar (figuras 1c, 2c). O androceu permanece incluso na corola, iniciando-se a deiscência das anteras. Neste momento, início da fase exclusivamente feminina, não há visitas; no entanto, o estigma pode receber grãos de pólen de flores próximas, as quais tiveram seus dispositivos de liberação de grãos de pólen acionados. Além disso, pode ocorrer transferência de pólen para estes estigmas pelo contato ocasional dos polinizadores, ao visitarem flores da mesma inflorescência. A fase feminina prossegue com o afastamento gradual das sépalas e dos lacínios, de modo que as flores adquirem uma forma tubular. Nesta fase, iniciam-se a secreção do néctar, a emissão de odor e as visitas, mas os dispositivos de liberação de grãos de pólen não podem ainda ser acionados. Tais observações mostram que nas espécies em estudo ocorre protoginia e a fase feminina das flores passa por dois momentos subsequentes: um, em que a corola está fechada e apenas o estigma, receptivo, encontra-se exteriorizado, e outra em que a corola adquire uma forma tubular, decorrente do início da abertura dos lacínios. Ao todo, a fase feminina das flores prolonga-se pelo primeiro dia de antese.

A abertura total da corola em ambas as espécies só ocorre no dia seguinte, quando passam a ser funcionalmente hermafroditas (figuras 1d-e, 2d-e). A fase hermafrodita tem também duração de um dia. Nesta segunda fase, o estigma permanece receptivo e as anteras, ainda envolvidas pelos lacínios, tornam-se totalmente deiscentes e aptas a se deslocarem dos mesmos, mediante o toque dos polinizadores. A emissão de odor e as visitas intensificam-se na fase hermafrodita das flores, o que é corroborado pelo maior número de grãos de pólen sobre a área estigmática de flores nesta fase. Estigmas na fase feminina apresentam cerca de $30 \%$ do total de grãos de pólen observados na fase hermafrodita $(n=10$ estigmas para cada espécie).

Nas flores em pós-antese todos os dispositivos lacínios-estames estão acionados e as anteras encontram-se vazias. Os lacínios entram em senescência, caindo posteriormente toda a corola, juntamente com o androceu, permanecendo o gineceu e as sépalas.

As flores de $M$. subsericea e de S. obtusifolium foram visitadas por insetos das ordens Hymenoptera, Lepidoptera, Coleoptera, Diptera e Thysanoptera. A relação dos visitantes, o tamanho aproximado dos mesmos, a frequência e horário das visitas e o seu comportamento intrafloral são apresentados na tabela 2 . Ambas as espécies compartilham, praticamente, os mesmos visitantes florais e são visitadas nas fases feminina (formato tubular) e hermafrodita.

As abelhas Xylocopa ordinaria e Apis mellifera, a vespa Brachygastra lecheguana e a borboleta Isanthrene 
incendiaria são os polinizadores efetivos das flores de $M$. subsericea e de $S$. obtusifolium, das quais retiram o néctar. Todos estes insetos promovem a liberação dos grãos de pólen, fazendo com que ocorra a deposição de pólen sobre a porção ventral do corpo dos mesmos. Para que isso ocorra é necessário que o visitante toque com as pernas no ápice dos lacínios medianos nas visitas às flores de ambas as espécies. Para alcançar o néctar, os polinizadores pousam sobre a flor de $M$. subsericea, inserindo o aparelho bucal no interior do tubo floral; em S. obtusifolium, a probóscide passa entre os estaminódios fletidos sobre o ovário, o que torna mais difícil o acesso ao néctar.

Durante a visita do polinizador, pode haver a liberação de pólen de uma ou mais anteras. A transferência de pólen

Tabela 2. Comportamento, frequência, tamanho, horário da visita e presença de grãos de polén no corpo dos visitantes florais de Manilkara subsericea e Sideroxylon obtusifolium na restinga de Maricá, Rio de Janeiro. (Frequência relativa: $1=$ pouco frequente $(<50 \%) ; 2=$ frequente $(\geq 50 \% \mathrm{e}<90 \%) ; 3=$ muito frequente $(>90 \%) ; \mathrm{M} / \mathrm{T}=$ manhã e tarde; $\mathrm{M}=$ manhã; $\mathrm{N}=$ noite; $\mathrm{Pe}=$ polinizador efetivo; $\mathrm{Po}=$ polinizador ocasional; $\mathrm{Pn}=$ pilhador de néctar; $\mathrm{Pp}=$ pilhador de pólen).

Table 2. Behaviour, frequency, size, time of visit and presence of pollen grains on the body of the flower visitors of Manilkara subsericea and Sideroxylon obtusifolium in restinga of Maricá, Rio de Janeiro. (Relative frequency: $1=$ low frequent $(<50 \%)$; $2=$ frequent $(\geq 50 \%$ and $<90 \%) ; 3=$ very frequent $(>90 \%) ; \mathrm{M} / \mathrm{T}=$ morning and afternoon; $\mathrm{M}=$ morning; $\mathrm{N}=$ night; $\mathrm{Pe}=$ effective pollinator; $\mathrm{Po}=$ occasional pollinator; $\mathrm{Pn}=$ nectar robber; $\mathrm{Pp}=$ pollen robber).

\begin{tabular}{|c|c|c|c|c|c|}
\hline \multirow{2}{*}{ Visitantes florais } & \multicolumn{2}{|c|}{$\begin{array}{l}\text { Comportamento/ } \\
\text { Frequência }\end{array}$} & \multirow{2}{*}{$\begin{array}{l}\text { Tamanho } \\
(\mathrm{mm})\end{array}$} & \multirow{2}{*}{ Visita } & \multirow{2}{*}{$\begin{array}{l}\text { Presença de } \\
\text { pólen }\end{array}$} \\
\hline & $\begin{array}{l}\text { Manilkara } \\
\text { subsericea }\end{array}$ & $\begin{array}{l}\text { Sideroxylon } \\
\text { obtusifolium }\end{array}$ & & & \\
\hline \multicolumn{6}{|l|}{ Hymenoptera } \\
\hline Xylocopa ordinaria Smith, 1874 & $\mathrm{Pe} / 2$ & $\mathrm{Pe} / 1$ & 15,0 & $\mathrm{M} / \mathrm{T}$ & Sim \\
\hline Apis mellifera Linnaeus, 1758 & $\mathrm{Pe} / 3$ & $\mathrm{Pe} / 3$ & 10,6 & $\mathrm{M} / \mathrm{T}$ & Sim \\
\hline Trigona spinipes (Fabricius, 1793) & $\mathrm{Po} / 3$ & $\mathrm{Po} / 1$ & 6,4 & $\mathrm{M} / \mathrm{T}$ & Sim \\
\hline Brachygastra lecheguana (Latreille, 1824) & $\mathrm{Pe} / 2$ & $\mathrm{Pe} / 2$ & 7,9 & $\mathrm{M} / \mathrm{T}$ & Sim \\
\hline Formiga 1 & $\mathrm{Pn} / 3$ & $\mathrm{Pn} / 2$ & 3,7 & $\mathrm{M} / \mathrm{T}$ & Não \\
\hline Formiga 2 & $\operatorname{Pn} / 3$ & - & 2,2 & $\mathrm{M} / \mathrm{T}$ & Não \\
\hline \multicolumn{6}{|l|}{ Lepidoptera } \\
\hline Isanthrene incendiaria Hübner, 1809 & $\mathrm{Pe} / 3$ & $\mathrm{Pe} / 3$ & 19,0 & $\mathrm{M} / \mathrm{T}$ & Sim \\
\hline Ascia monuste orseis Godart, 1819 & $\mathrm{Pn} / 2$ & - & 15,0 & M & - \\
\hline Urbanus procne Plötz, 1880 & $\mathrm{Pn} / 1$ & - & 20,0 & M & - \\
\hline Microlepidóptero & $\mathrm{Pn} / 1$ & - & 3,1 & M & Não \\
\hline Microlepidóptero & $\mathrm{Pn} / 1$ & - & 4,4 & M & Não \\
\hline \multicolumn{6}{|l|}{ Coleoptera } \\
\hline Astylus lineatus Fabricius, 1775 & $\operatorname{Pn} / 3$ & $\mathrm{Pn} / 3$ & 6,6 & $\mathrm{M} / \mathrm{T}$ & Sim \\
\hline Clytrinae & $\mathrm{Pn} / 3$ & - & 1,3 & $\mathrm{M} / \mathrm{T}$ & Sim \\
\hline Oedemeridae & $\mathrm{Pn} / 3$ & $\mathrm{Pn} / 3$ & 2,0 & $\mathrm{M} / \mathrm{T}$ & Sim \\
\hline Curculionidae & $\mathrm{Pn} / 3$ & - & 2,4 & $\mathrm{M} / \mathrm{T}$ & - \\
\hline Oedemeridae & $\mathrm{Pp} / 3$ & - & 7,0 & $\mathrm{M} / \mathrm{T}$ & Sim \\
\hline \multicolumn{6}{|l|}{ Diptera } \\
\hline Culicidae & $\mathrm{Pn} / 1$ & - & 5,7 & $\mathrm{~N}$ & Não \\
\hline \multicolumn{6}{|l|}{ Thysanoptera } \\
\hline Thrips sp. & $\mathrm{Pn} / 3$ & $\mathrm{Pn} / 1$ & 1,0 & $\mathrm{M} / \mathrm{T} / \mathrm{N}$ & Sim \\
\hline
\end{tabular}


para a área estigmática ocorre a partir da porção ventral dos polinizadores, caracterizando uma polinização do tipo esternotríbica. Embora na fase feminina (flores semi-abertas com formato tubular) as flores também sejam visitadas, na fase hermafrodita, por serem mais atrativas, tanto visualmente como olfativamente, e por oferecerem melhor acesso ao néctar, as visitas são mais numerosas.

Xylocopa ordinaria e Brachygastra lecheguana visitam as flores das duas espécies predominantemente na parte da manhã e, ainda que não sejam muito frequentes, sempre promovem a liberação dos grãos de pólen e tocam na área estigmática.

Apis mellifera é a abelha mais frequente e abundante, podendo ser observada visitando as flores de ambas as espécies ao longo de todo o dia. Em um vôo de forrageio, visita muitas flores de uma mesma inflorescência, permanecendo muito tempo numa mesma planta.

Trigona spinipes, por sua vez, visita as flores de ambas as espécies, ora atuando como polinizador e ora como pilhador de néctar. No primeiro caso, esta abelha aborda as flores por cima e apóia-se nos lacínios medianos, promovendo a liberação do pólen e tocando na área estigmática receptiva. No segundo caso, $T$. spinipes aborda as flores de $M$. subsericea pousando sobre os lacínios laterais, deflexos, e coleta o néctar por entre os lacínios medianos. Já nas flores de S. obtusifolium, pousa sobre o cálice e pilha o néctar por entre os estaminódios.

A borboleta Isanthrene incendiaria, em função de seu porte grande, pousa sobre as inflorescências e se move lentamente sobre as mesmas em busca de néctar, podendo contactar diferentes áreas estigmáticas e estames ao mesmo tempo. Durante o estudo foi possível observar até oito indivíduos em uma mesma planta. Em S. obtusifolium as visitas ocorrem principalmente nas inflorescências localizadas no interior da copa.

Os besouros Astylus linneatus e Oedemeridae também foram observados frequentemente em ambas as espécies, ao longo de todo o dia, às vezes em grupos de cerca de 20 indivíduos por planta, atuando principalmente como pilhadores de néctar e de pólen, embora em algumas visitas possam tocar na área estigmática de ambas as espécies. Por diversas vezes estes besouros foram observados pilhando o pólen já liberado e depositado sobre os lacínios e ovários. Nas flores de S. obtusifolium também foram observados realizando coleta ativa de grãos de pólen diretamente das anteras, sem promover a liberação explosiva dos mesmos. Para isto, os besouros introduzem o aparelho bucal ao longo do lacínio mediano até a região de inserção das anteras, tendo acesso ao pólen.
Os demais visitantes registrados (Formigas, Diptera e Thysanoptera) são apenas pilhadores de néctar porque abordam as flores lateralmente ou por baixo (estando sobre as sépalas), sendo incapazes de acionar os estames ou de tocar na área estigmática.

\section{Discussão}

Oestudo da morfologia das flores de Sapotaceae levou Pennington (1991) a relacionar cinco tipos florais para a família, a saber: tipo Mimusops, Madhuca, Sideroxylon, Pradosia e Pouteria. As flores de Manilkara subsericea foram caracterizadas como do tipo Mimusops, o mais complexo da família. Neste tipo, o cálice é bisseriado, com três ou quatro sépalas por série; a corola é curtotubulosa e os lacínios, de comprimento maior que o tubo, abrem-se totalmente, expondo os estaminódios e estames eretos. Os lacínios são divididos formando segmentos petalóides de mesmo tamanho e a maioria das espécies tem sépalas, lacínios, estames e estaminódios em mesmo número, podendo apresentar redução dos apêndices em alguns casos. Já as flores de Sideroxylon obtusifolium foram incluídas no tipo Sideroxylon, caracterizado por flores pentâmeras; cálice unisseriado formado por cinco sépalas imbricadas; corola curto-tubulosa, com lacínios subdivididos em três segmentos, os dois laterais muito reduzidos em relação ao médio, ausentes em alguns casos; estames adnados no terço superior do tubo da corola, exteriorizados e alternos com cinco estaminódios de desenvolvimento variável; estilete curto.

Muito embora os caracteres morfológicos das flores de M. subsericea e de S. obtusifolium levem à classificação das mesmas em tipos florais diferentes (Pennington 1991), o presente estudo demonstrou que as duas espécies são semelhantes com relação à biologia floral e aos mecanismos de polinização, principalmente, no que se refere à protoginia, hercogamia, forma de liberação dos grãos de pólen e polinizadores.

Manilkara subsericea e $S$. obtusifolium apresentam dicogamia, com duas fases sexuais subsequentes ocorrendo ao longo do período de atividade das flores: a primeira, funcionalmente feminina, quando apenas os estigmas estão accessíveis, ainda nas flores semi-abertas, e a outra hermafrodita. A dicogamia consiste na separação temporal da expressão sexual das flores, caracterizando-se pela receptividade estigmática e a liberação dos grãos de pólen em diferentes momentos, podendo ser completa ou incompleta, em função do grau de separação dessas duas funções (Lloyd \& Webb 1986). No caso das espécies estudadas, a dicogamia é protogínica e incompleta já que o período com apresentação exclusiva dos estigmas 
receptivos antecede uma fase em que estigmas e grãos de pólen são apresentados ao mesmo tempo. O longo período de receptividade do estigma é referido, para diferentes espécies, como uma forma de aumentar a deposição de pólen sobre a superfície receptiva, promovendo, assim, a multipaternidade, a competição entre gametófitos e o maior vigor da progênie (Spira et al. 1992).

$\mathrm{Na}$ família Sapotaceae há relatos de protoginia para Bumelia salicifolia (=Sideroxylon), Manilkara bahamensis (Tomlinson 1974) e Argania spinosa (Nerd et al. 1998). Para as duas primeiras espécies, Tomlinson (1974) se refere às fases "carpelar e estaminada" das flores, sem fazer qualquer consideração sobre a receptividade estigmática, o que sugere que a protoginia tenha sido registrada apenas em função da exteriorização do estilete nas flores com corola ainda não expandida. Já para Argania spinosa, Nerd et al. (1998) caracterizaram diferentes estádios do desenvolvimento das flores e comprovaram que quando o estilete emerge no topo do botão fechado, o estigma já se encontra receptivo, apresentando de 60 a 70\% de grãos de pólen germinados, percentual que se mantém ao longo da antese. Em Madhuca indica, Kuruvilla \& Shah (1988) investigaram mudanças histológicas e histoquímicas durante o desenvolvimento do estigma e estilete e registraram presença de exsudato abundante, visível, com evidências de lipídios, proteínas e polissacarídeos, a partir do "estádio III das flores - botão desenvolvido com estilete exteriorizado". Somente a partir deste estádio, estigmas polinizados mostraram grãos de pólen emitindo tubos polínicos. Nas espécies aqui estudadas a receptividade estigmática também é indubitavelmente marcada pela secreção e brilho, o que permite constatar a ocorrência de protoginia nas mesmas. Tal fato é corroborado pelas observações de visitantes nas flores semi-abertas (forma tubular), com estilete exteriorizado e pela presença de grãos de pólen germinando na fase feminina em flores polinizadas naturalmente. Em Sapotaceae também há registros de dicogamia protândrica para as espécies Chrysophyllum auratum Miquel e C. oliviforme L. (Tomlinson 1974, Corrales et al. 1986).

Heslop-Harrison \& Shivanna (1977) propuseram uma classificação para os estigmas de Angiospermas baseados nas características anatômicas e fisiológicas de suas superfícies, cobrindo cerca de 1000 espécies, de 900 gêneros, em 250 famílias. Os referidos autores classificaram os estigmas de Lucuma (=Pouteria), únicos representantes da família Sapotaceae no trabalho, como secos e com papilas unicelulares. No entanto, os estigmas úmidos e papilosos das espécies aqui estudadas mostram que a família apresenta diversidade com relação a esse caráter. Na família Sapotaceae há registro de estigma com características semelhantes aos das espécies aqui estudadas para Madhuca indica (Kuruvilla \& Shah 1988, Endress 1994).

Nossos resultados mostraram que nas flores de M. subsericea e S. obtusifolium, apesar das anteras estarem deiscentes ainda nas flores semi-abertas (fase feminina), não há a possibilidade dos grãos de pólen serem liberados em função da total separação espacial (hercogamia) entre o estilete/estigma (exteriorizados) e o androceu (incluso no cálice e na corola, ambos não expandidos nesta fase). A liberação dos grãos de pólen só ocorre no estádio em que as flores estão totalmente abertas (fase hermafrodita) e depende do toque dos polinizadores no ápice dos lacínios medianos, capaz de promover o acionamento do estame e a liberação de grãos de pólen na forma de "nuvem". Nesse estádio, as flores de $M$. subsericea de $S$. obtusifolium apresentam hercogamia de aproximação, ou seja, quando os polinizadores realizam visitas legítimas tocam primeiramente na área estigmática, transferindo grãos de pólen do seu corpo para a mesma, antes de receberem a carga de grãos de pólen liberada pela explosão. Não foi encontrada referência para este tipo de liberação dos grãos de pólen em espécies de Sapotaceae, sendo o presente estudo o primeiro registro do mecanismo de liberação explosiva de pólen para a família.

A liberação explosiva dos grãos de pólen pode ser encontrada em flores ornitófilas, como Calathea timothei H. Kenn. e Saranthe klotzschiana (Koer.) Eichl. (Marantaceae) (Locatelli et al. 2004), Mucuna sp. nov. Faboideae (Fabaceae) (Agostini 2004); em flores quiropterófilas, como algumas espécies de Mucuna (van der Pijl 1941 apud Brantjes \& de Vos 1981); e miófilas, como em Lopezia sp. (Onagraceae) que apresenta a liberação explosiva em combinação com a protandria (Hildebrand 1866 apud Brantjes \& de Vos 1981) e por abelhas e vespas, como em Hyptis capitata Jacq. (Labiatae) (Keller \& Arbruster 1989).

Diferentes famílias apresentam o mecanismo de liberação explosiva dos grãos de pólen, a saber: Dipterocarpaceae (Atluri et al. 2004), Musaceae (Proctor \& Yeo 1975), Labiatae (Keller \& Arbruster 1989), Leguminosae (Westerkamp \& Paul 1993), Loranthaceae (Proctor \& Yeo 1975) e Marantaceae (Locatelli et al. 2004). No entanto, nestas famílias, a liberação difere da descrita para as espécies de Sapotaceae, pelo fato de todos os estames estarem inseridos na corola e serem acionados juntos, enquanto que em $M$. subsericea e S. obtusifolium há dispositivos que funcionam independentemente. Durante as visitas dos polinizadores, cada estame é 
acionado isoladamente, tendo como consequência o prolongamento da fase de apresentação de pólen, ou seja, os polinizadores podem capturar grãos de pólen em um número maior de ocasiões, o que propicia uma maior possibilidade nos cruzamentos (Lloyd \& Yates 1982). A liberação explosiva de pólen através de um dispositivo acionado somente pelos polinizadores evita que a remoção de pólen por visitantes florais pilhadores reduza a quantidade de pólen disponível, com consequências favoráveis para a polinização cruzada.

Tomlinson (1974) ressalta que as Sapotaceae do Sul da Flórida exibem variedade de mecanismos florais e que, em algumas espécies, as estruturas florais são complexas em função da presença de segmentos petalóides e estaminódios, cuja morfologia foi muito discutida, mas as funções pouco consideradas. Destaca-se que nas duas espécies aqui estudadas os segmentos da corola e os estaminódios estão relacionados com a atração visual e olfativa dos polinizadores, ao passo que a liberação de uma nuvem de grãos de pólen é decorrente da associação entre o lacínio mediano e o estame. A liberação de grãos de pólen em forma de "nuvem" é frequentemente associada às espécies com anteras poricidas que dependem da vibração do polinizador, a fim de que os grãos de pólen sejam liberados. Neste caso, ocorre uma transferência energética para os estames, promovendo a liberação de uma "nuvem" de grãos de pólen (Buchmann 1983). A forma de liberação de grãos de pólen nas espécies estudadas tem semelhança com a que ocorre com anteras poricidas, no sentido de que, nos dois casos, há dependência de uma ação do polinizador. No entanto, em flores com anteras poricidas, a energia necessária para a liberação dos grãos de pólen vem do movimento vibratório dos músculos indiretos de vôo das abelhas (Buchmann 1983), ao passo que nas espécies estudadas a energia necessária vem do toque do polinizador sobre o lacínio e deste sobre as anteras.

O tamanho pequeno e a exina seca e pouco esculturada são características que favorecem a forma de liberação dos grãos de pólen de $M$. subsericea e S. obtusifolium. Essas mesmas características estão presentes em grãos de pólen de flores com deiscência poricida (Silva et al. 2002) ou com deiscência rimosa (Moço \& Pinheiro 1999), que dependem da vibração dos estames a fim de que o pólen seja transferido das anteras para o polinizador.

Em Sapotaceae, o estudo da biologia da polinização é bastante escasso, tendo-se poucos dados sobre os seus visitantes e polinizadores efetivos. Particularmente para o gênero Manilkara, há relatos de polinização por morcegos e por Thysanoptera (Pennington 1990). As flores de M. salzammii (A. DC.) Lam. são visitadas por abelhas Xylocopa sp., Apis mellifera e Trigona spinipes (Viana \& Kleinert 2006). Os estudos sobre polinização em Sideroxylon restringem-se a $S$. cinereum Lam. e S. puberulum DC., espécies dióicas e ornitófilas das Ilhas Maurício, polinizadas por Zosterops borbonicus mauritianus Gmelin e Z. chloronothos Vieillot e cujas flores também são intensamente visitadas por Apis mellifera, que provavelmente interfere nas interações endêmicas entre as duas espécies de Sapotaceae e os dois pássaros (Hansen et al. 2002).

Os resultados apresentados confirmam para as duas espécies: a protoginia, com registro do início da receptividade do estigma por ocasião da exteriorização do estilete, antes mesmo da abertura da corola; a liberação explosiva de grãos de pólen, ocasionada pela liberação dos estames, alojados sob tensão nos lacínios medianos, através da ação de um polinizador; a identificação dos insetos Xylocopa ordinaria, Apis mellifera, Brachygastra lecheguana e Insanthrene incendiaria como polinizadores das flores, uma vez que são capazes não só de promover a liberação da "nuvem" de grãos de pólen, mas também de transferi-los para as superfícies estigmáticas receptivas.

Agradecimentos - Ao CNPq e a Faperj, pelo apoio financeiro. Ao Laboratório de Biologia da Reprodução de Angiospermas, Departamento de Botânica do Museu Nacional/UFRJ por toda ajuda ao longo deste trabalho. À bióloga e desenhista Lívia Botinhão pela elaboração da prancha. À Profạ. Valéria Maia, aos biólogos Paulo Magno e Alexandre Soares do Museu Nacional/UFRJ pela identificação dos insetos.

\section{Referências bibliográficas}

AGOSTINI, K. 2004. Ecologia da polinização de Mucuna sp. nov. (Fabaceae) no litoral norte de São Paulo, Brasil. Dissertação de mestrado, Universidade Estadual de Campinas, Campinas.

ALEXANDER, M.P. 1980. A versatile stain for pollen, fungi yeast and bacteria. Stain Tecnology 55:13-18.

ATLURI, J.B., VENKATA RAMANA, S.P. \& SUBBA REDDI, C. 2004. Explosive pollen release, windpollination and mixed matting in the tropical tree Shorea robusta Gaertn. F. (Dipterocarpaceae). Current Science 86:1416-1419.

BAWA, K.S. 1974. Breeding systems of tree species of a lowland tropical community. Evolution 28:85-92.

VIANA, B.F. \& KLEINERT, A.M.P. 2006. Sctruture of bee-flower system in the coastal sand dune of Abaeté, northeastern Brazil. Revista Brasileira de Entomologia 50:53-63. 
BRANTJES, N.B.M. \& DE VOS, O.C. 1981. The explosive release of pollen in flowers of Hyptis (Lamiaceae). New Phytology 87:425-430.

BUCHMANN, S.L. 1983. Buzz pollination in Angiosperms. In Handbook of Experimental Pollination Biology (C.E. Jones \& R.J. Little, eds.), New York, p.73-113.

CORRALES, F.M., MANTOVANI, W. \& CATHARINO, E.L.M. 1986. Estudos preliminares da biologia floral de Chrysophyllum auratum Miq. (Sapotaceae) em Piracicaba, Estado de São Paulo. Anais da Escola Superior de Agricultura Luiz de Queiroz 43:147-157.

ENDRESS, P.K. 1994. Diversity and evolutionary biology of tropical flowers. Cambridge Univerity Press, Cambridge.

FERREIRA, R. DE C.N. 2000. Espécies arbóreas ameaçadas de extinção das restingas do norte fluminense. Considerações sobre sua conservação mediante ao emprego paisagístico. Dissertação de mestrado, Universidade Federal do Rio de Janeiro, Museu Nacional, Rio de Janeiro.

GAHAN, P.B. 1984. Plant histochemistry and cytochemistry - An introdution. Academic Press, London.

HANSMAN, D.H. 2001. Floral biology of dry rainforest in north Queensland and a comparison with adjacent Savanna woodland. Australian Journal of Botany 49:137-153.

HANSEN, D.M., OLESEN, J.M. \& JONES, C.G. 2002. Trees, birds and bees in Mauritius: exploitative competition between introduced honey bees and endemic nectarivorous birds? Journal of Biogegraphy 29:721-734.

HEITHAUS, E.R., FLEMING, T.H. \& OPLER, P.A. 1975. Foraging patterns and resource utilization in seven species of bats in a seasonal tropical forest. Ecology 56:841-854.

HESLOP-HARRISON, Y. \& SHIVANNA, K.R. 1977. The receptive surface of the Angiosperm stigma. Annals of Botany 41:1233-1258.

IBAMA. 1992. Lista Oficial de Flora Ameaçada de Extinção. Através da Portaria № 37-N de 3 de abril de 1992. http://www.ibama.gov.br/flora/extincao.htm (acesso em 27/11/2007).

JOHANSEN, D.A. 1940. Plant microtechnique. MacGrawHill Book Company, New York.

JUDD, W.S., CAMPBELL, C.S., KELlOGG, E.A. \& STEVENS, P.F. 1999. Plants systematics. A phylogenetic approach. Sinauer, Sunderland.

KELLER, S. \& ARBRUSTER, S. 1989. Pollination of Hyptis capitata bys wasps in Panama. Biotropica 21:190-192.

KURUVILLA, P.K. 1989. Pollination biology, seed setting and fruit setting in Madhuca indica (Sapotaceae). Indian Forest 22-28.

KURUVILLA, P.K. \& SHAH, J.J. 1988. Development and histochemistry of style and stigma, and pollen-pistil interaction in Madhuca indica (Sapotaceae). Annals of Botany 61:269-281.
LEVIN, D.A. \& BERUBE, D.E. 1972. Phlox and Colias: the efficiency of a pollination system. Evolution 26: 242-250.

LLOYD, D.G. \& YATES, J.M.A. 1982. Intrasexual selection and the segregation of pollen in stigmas in hermaphrodite plants exemplified by Wahlembergia albomarginata (Campanulaceae). Evolution 36:903-913.

LLOYD, D.G. \& WEBB, C.J. 1986. The avoidance of interference between the presentation of pollen and stigmas in angiosperms. I. Dichogamy. New Zealand Journal of Botany 24:135-162.

LOCATELLI, E., MACHADO, I.C. \& MEDEIROS, P. 2004. Saranthe klotzschiana (Koer.) Eichl. (Marantaceae) e seu mecanismo explosivo de polinização. Revista Brasileira de Botânica 27:757-765.

MANTOVANI, A. \& IGLESIAS, R.R. 2001. Bromélias terrestres na restinga de Barra de Maricá, Rio de Janeiro: Influência sobre o microclima, o solo e a estocagem de nutrientes em ambientes de borda de moitas. Leandra 16:17-37.

MELLO-FILHO, L.E., SOMNER, G.V. \& PEIXOTO, A.L. 1992. Centuria Plantarum Brasiliensium Exstintionis Minitata. Sociedade Botânica do Brasil/Ibama, Brasília.

MOÇO, C.C. \& PINHEIRO, M.C.B. 1999. Pollination ecology of Swartzia apetala Raddi var. apetala (Leguminosae-Papilionoideae). Brazilian Archives of Biology and Technology 42:415-423.

NERD, A., IRIDJIMOVICH, V. \& MIZRAHI, Y. 1998. Phenology, breeding system and fruit development of Argan (Argan spinosa, Sapotaceae) cultivated in Israel. Economic Botanic 52:161-167.

ORMOND, W.T., PINHEIRO, M.C.B., LIMA, H.A. DE, CORREIA, M.C.R. \& PIMENTA, M.L. 1993. Estudo das recompensas florais de plantas de restinga de Maricá - Itaipuaçu, RJ. I - Nectaríferas. Bradea 6: 179-195.

PENNINGTON, T.D. 1990. Flora Neotropica: Sapotaceae, New York.

PENNINGTON, T.D. 1991. The genere of Sapotaceae. United Kingdom. New York Botanical Garden e Kew, New York.

PROCTOR, M. \& YEO, P. 1975. The pollination of flowers. Editora Willian Collins Sons \& Co Ltd., London.

REITZ, P.P. 1968. Flora Ilustrada Catarinense. Sapotáceas. Itajaí, Santa Catarina.

RIBEIRO, J.E. DA S., HOPKINS, M.J.G., VICENTINI, A., SOTHERS, C.A., COSTA, M.A. DA S., BRITO, J.M. DE, SOUZA, M.A.D. DE, MARTINS, L.H.P., LOHMANN, L.G., ASSUNÇÃO, P.A.C.L., PEREIRA, E. DA C., SILVA, C.F. DA, MESQUITA, M.R. \& PROCÓPIO, L.C. 1999. Flora da Reserva Ducke. Guia de identificação das plantas vasculares de uma floresta de terra firme na Amazônia Central. INPA - DFID, Manaus. 
SILVA, I.M. DA \& OLIVEIRA, A.S. DE. 2001. Sapotaceae. In Flora do Parque Nacional da Restinga de Jurubatiba e arredores, Rio de Janeiro, Brasil: listagem, florística e fitogeografia (A.F. da Costa \& I.C.A. Dias, eds.). Museu Nacional, Rio de Janeiro, Série livros, n.8. p.128.

SILVA, A.L.G., ORMOND, W.T. \& PINHEIRO, M.C.B. 2002. Biologia floral e reprodutiva de Senna australis (Vell.) Irwin \& Barneby (Fabaceae, Caesalpinioideae). Boletim do Museu Nacional 121:1-11.

SPIRA, T.P., SNOW, A.A., WHIGHAM, D.F. \& LEAK, A.J. 1992. Flower visitation, pollen deposition, and pollentube competition in Hibiscus moscheutos (Malvaceae). American Journal of Botany 79:428-433.
SUBBA REDDI, C. \& ATLURI, J.B. 1981. Floral biology of Mimusops elengi Linn. Journal of the Bombay Natural History Society 77:471-475.

TOMLINSON, P.B. 1974. Breeding mechanisms in trees. Journal of the Arnold Arboretum 55:269-290.

VOGEL, S. 1983. Ecophysiology of zoophilic pollination. In Physiological Plant Ecology III. Encyclopedia of plant physiology (O.L. Lange, P.S. Nobel., C.B. Osmond \& H. Ziegler, eds.). Springer-Verlag Berlin. Heidelberg, New Series, v.12C, p.559-624.

WESTERKAMP, C. \& PAUL, H. 1993. Apios americana, a fly-pollinated papilionaceous flower? Plant Systematics and Evolution 187:135-144. 